\title{
A clinical study of HELLP syndrome and its outcome in a tertiary health care system
}

\author{
Ashwini Mallesara*, Srushti R. Kanta, Prashanth Shivappa
}

Department of Obstetrics and Gynecology, Shivamogga Institute of Medical Sciences, Shivamogga, Karnataka, India

Received: 27 October 2016

Accepted: 02 November 2016

\section{*Correspondence:}

Dr. Ashwini Mallesara,

E-mail: ashwini.mallesara@gmail.com

Copyright: ( ) the author(s), publisher and licensee Medip Academy. This is an open-access article distributed under the terms of the Creative Commons Attribution Non-Commercial License, which permits unrestricted non-commercial use, distribution, and reproduction in any medium, provided the original work is properly cited.

\begin{abstract}
Background: The objective was to study the cases of HELLP syndrome and its management and outcome in a tertiary health care system.

Methods: Three Hundred Twenty patients with gestational age >20 weeks were selected whose BP recorded more than 140/90 mm Hg. This study was done from July 2014 to July 2016. Required laboratory investigations were carried out and the outcome was studied with respect to maternal and fetal outcome.

Results: The association with HELLP/ Partial HELLP was not significantly associated with the parity and the family history. There was a strong association of HELLP/ Partial HELLP with Pre eclampsia and all the three tests (hemolysis, liver enzymes, platelet count) that was considered to be the gold standard tests to identify the pathology. Conclusions: The association points towards only one point, that is to identify and treat the patients immediately in order to reduce maternal and neonatal morbidity and mortality.
\end{abstract}

Keywords: HELLP Syndrome, Hemolysis, Liver Enzyme, Platelets

\section{INTRODUCTION}

Louis Weinstein coined the term HELLP syndrome in 1982. ${ }^{1}$ There is considerable debate regarding the definition, diagnosis, incidence, etiology, and management of HELLP syndrome. A study done by Sibai $\mathrm{B} \mathrm{M}$ et al in 1985 reported an incidence of HELLP as $9.7 \%$ in his study. ${ }^{2}$ Another study done in 1993 reported the incidence as $20 \%$ of women with pre-eclampsia. ${ }^{3}$ Chances of increased risk of maternal death (1\%) was reported by another study. ${ }^{4}$ Patients with such findings were previously described by many investigators. Weinstein considered it a unique variant of preeclampsia and coined the term HELLP syndrome for this entity. Barton and associates performed liver biopsies in patients with preeclampsia and HELLP syndrome. Periportal necrosis and hemorrhage were the most common histopathologic findings. In addition, they found that the extent of the laboratory abnormalities in HELLP syndrome, including the platelet count and liver enzymes, did not correlate with hepatic histopathologic findings.
The classic findings of microangiopathic hemolysis include abnormal peripheral smear (schistocytes, burr cells, echinocytes), elevated serum bilirubin (indirect form), low serum haptoglobin levels, elevated lactate dehydrogenase (LDH) levels, and significant drop in hemoglobin levels. A significant percentage of published reports included patients who had no evidence of hemolysis; hence, these patients will fit the criteria for HELLP syndrome. In some studies in which hemolysis are described, the diagnosis is suspect because it has been based on the presence of an abnormal peripheral smear (no description of type or degree of abnormalities) or elevated LDH levels (threshold of 180 to $600 \mathrm{U} / \mathrm{L}$ ). There is no consensus in the literature regarding the liver function test to be used or the degree of elevation in these tests to diagnose elevated liver enzymes. In his original report, Weinstein mentioned abnormal serum levels of aspartate transaminase (AST), abnormal alanine transaminase (ALT), and abnormal bilirubin values; however, specific levels were not suggested. In subsequent studies in which elevated liver enzymes were 
described (either AST or ALT), the values considered to be abnormal ranged from 17 to 72 U/L.85 In clinical practice, many of these values are considered normal or slightly elevated. Cardiopulmonary complications were reported more in patients who had ascites. ${ }^{5}$

Many authors have used elevated total LDH (usually $>600 \mathrm{U} / \mathrm{L}$ ) as a diagnostic criteria for hemolysis. There are five different isoforms of LDH, and only two of them, LDH1 and LDH2, are released from ruptured red blood cells. In most women with severe preeclampsiaeclampsia, the elevation in total LDH is probably caused mostly by liver ischemia. Therefore, many authors advocate that elevated bilirubin values (indirect form), abnormal peripheral smear, or a low serum heaptoglobin level should be part of the diagnostic criteria for hemolysis. This is based on the study conducted in their regional population. Based on a retrospective review of 302 cases of HELLP syndrome, Martin and colleagues devised the following classification based on the nadir of the platelet count. Class I HELLP syndrome was defined as a platelet nadir below $50,000 / \mathrm{mm} 3$, class 2 as a platelet nadir between 50,000 and $100,000 / \mathrm{mm} 3$, and class 3 as a platelet nadir between 100,000 and $150,000 / \mathrm{mm} 3$. These classes have been used to predict the rapidity of recovery postpartum, maternal perinatal outcome, and the need for plasmapheresis.

Hemolysis, defined as the presence of microangiopathic hemolytic anemia, is the hallmark of HELLP syndrome. The role of disseminated intravascular coagulation (DIC) in preeclampsia is controversial. Most authors do not regard HELLP syndrome to be a variant of DIC because coagulation parameters such as prothrombin time, partial thromboplastin time, and serum fibrinogen are normal. However, the diagnosis of DIC can be difficult to establish in clinical practice. When sensitive determinants of this condition are used, such as antithrombin III, fibrinopeptide A, fibrin monomer, D-dimer, oczantiplasmin, plasminogen, prekallikrein, and fibronectin, many patients have laboratory values consistent with DIC. Unfortunately, these tests are time consuming and not suitable for routine monitoring. Consequently, less sensitive parameters are often employed. Sibai and associates defined as the presence of thromhocytopenia, low fibrinogen levels (plasma fibrinogen <30l) mg/dl.), and fibrin split products above $40 \mathrm{mg} / \mathrm{dl}$. These authors noted the presence of DIC in $21 \%$ of 442 patients with HELLP syndrome. They also found that most cases occurred in women who had antecedent abruptio placentae or peripartum hemorrhage and in all four women who had subcapsular liver hematomas. In the absence of these complications, the frequency of DIC was only $5 \%$. Many were diagnosed to have liver hematomas also. The rate of preterm delivery is also high. So the infants have a high rate of neonatal complications ${ }^{6}$.

The disease has to be diagnosed as early as possible. Delay in diagnosis is associated with mortal consequence. ${ }^{7}$ Majority of the patients need blood transfusion. ${ }^{8}$ The study is intended to help the practicing gynecologists and obstetricians to diagnose early and act fast so as to put a break in its natural progression.

\section{METHODS}

A prospective observational study was carried out in the high risk pregnancy ward of District Government Hospital, Department of Obstetrics and Gynecology, Shivamogga Medical College, Shivamogga. This study was done from July 2014 to July 2016.

The study was approved by Institutes scientific and Ethics Committee. All the cases recruited were informed of the study and their written consent was obtained. Sample size required was calculated on the basis of incidence for HELLP syndrome in the hospital to obtain the results with $95 \%$ confidence interval.

Three hundred twenty patients were selected whose BP was recorded more than 140/90 mm $\mathrm{Hg}$. Hemolysis detected by either Peripheral smear or elevated Indirect bilirubin or elevated LDH levels. Elevated liver enzymes and Decreased Platelet count $<100,000 /$ cumm was noted. Incidence of HELLP syndrome was found and the various clinical features presented and the complications faced by the patients were recorded. Prompt Treatment was given and the outcome of the disease was noted.

\section{Inclusion criteria}

1. All pregnant women above 20 weeks of gestational age with $\mathrm{BP}>140 / 90 \mathrm{~mm}$ of $\mathrm{Hg}$

2. Patients with Pre-eclampsia / Eclampsia

\section{Exclusion criteria}

1. Known case of Hepatic disease.

2. Known case of Hemolytic Anaemias.

3. Known case of Platelet disorders.

All the statistical analysis was done using the latest SPSS version 17.0 and $p$ value $<0.05$ was considered significant. Statistical method applied to analyse the data was chi square test.

\section{RESULTS}

The present study has 320 patients with age ranging between 19-26yrs, with mean age of 21.34yrs.

Table 1: Mean age of the study participants $(n=320)$.

\begin{tabular}{|c|c|c|}
\hline & Mean & Std. deviation \\
\hline Age & 21.34 & 3.74 \\
\hline
\end{tabular}

Among 320 patients, 38 patients have HELLP/ Partial HELLP. Out of them 22 are primigravida and 16 are multigravida (Table 2). 
Table 2: Association of HELLP/ Partial HELLP syndrome with Parity and Family History $(n=320)$.

\begin{tabular}{|llll|}
\hline Parity & Multi & $\mathrm{X}^{2}$ value & $\mathrm{p}$ value \\
\hline Primi & 16 & 2.542 & 0.468 \\
\hline 22 & $\mathrm{X}^{2}$ value & $\mathrm{p}$ value \\
\hline $\begin{array}{l}\text { Family History of Pre } \\
\text { Eclampsia }\end{array}$ & 3.065 & 0.079 \\
\hline 7 & 31 & 3 \\
\hline
\end{tabular}

Out of 38 patients 7 had family h/o of pre eclampsia and 31 had no family h/o pre eclampsia. Whereas in remaining 282 patients without HELLP syndrome 260 f they had family h/o pre eclampsia. Both parity and family history of pre eclampsia are found to be insignificant in the present study.

Table 3: Association of HELLP with Pre-Eclampsia and All three diagnostic features $(n=320)$ (hemolysis, elevated liver enzymes, low platelet count).

\begin{tabular}{|c|c|c|c|}
\hline \multicolumn{2}{|c|}{$\begin{array}{l}\text { Diagnostic criteria (All 3) } \\
\text { (HELLP) }\end{array}$} & \multirow{2}{*}{$\begin{array}{l}\mathrm{X}^{2} \\
\text { value }\end{array}$} & \multirow{2}{*}{$\begin{array}{l}p \\
\text { value }\end{array}$} \\
\hline Present & Absent & & \\
\hline 16 & 304 & 12.988 & 0.005 \\
\hline \multicolumn{2}{|c|}{ HELLP and partial HELLP } & \multirow{2}{*}{$\begin{array}{l}X^{2} \\
\text { value }\end{array}$} & \multirow{2}{*}{$\begin{array}{l}\mathrm{p} \\
\text { value }\end{array}$} \\
\hline Present & Absent & & \\
\hline 38 & 282 & 8.920 & 0.030 \\
\hline
\end{tabular}

Out of 320 patients 16 of them showed all three features of HELLP (hemolysis, elevated liver enzymes, low platelet count) and 22 of them have one or two of these features. So total of 38 patients have HELLP/Partial HELLP. In this study HELLP/partial HELLP syndrome is found to be significantly associated with all three diagnostic features.

Table 4: Mean laboratory findings in the HELLP syndrome.

\begin{tabular}{|ll|}
\hline Hb \% & 8.752gm \% \\
\hline Reticulocyte count (\%) & 2.163 \\
\hline Platelet count (cmm) & 119725 \\
\hline LDH (u/l ) & 1065.73 \\
\hline Total bilirubin (mg /dl) & 3.17 \\
\hline AST (u/l ) & 146.34 \\
\hline ALT (u/l ) & 139.74 \\
\hline Haemolysis in peripheral blood smear $(\mathrm{n})$ & 38 \\
\hline
\end{tabular}

The above Table shows mean laboratory findings of 38 patients with HELLP syndrome. Here $\mathrm{Hb} \%$ is markedly decreased with significant rise in LDH and liver enzymes. Peripheral smear of all 38 showed features of haemolysis with low platelet count.

The mean systolic BP and diastolic BP is $192.62 \mathrm{~mm} \mathrm{Hg}$ and $113.17 \mathrm{~mm} \mathrm{Hg}$ respectively among HELLP syndrome patients (Table 5).
Table 5: Mean BP findings in the HELLP syndrome.

\begin{tabular}{|c|c|}
\hline Type & \\
\hline Systolic BP & $192.62 \mathrm{~mm} \mathrm{Hg}$ \\
\hline Diastolic BP & $113.17 \mathrm{~mm} \mathrm{Hg}$ \\
\hline
\end{tabular}

Table 6: Maternal complications.

\begin{tabular}{|c|c|}
\hline \multicolumn{2}{|l|}{ Complications } \\
\hline Abruptio placentae & 09 \\
\hline DIC & 11 \\
\hline Cerebral oedema & 4 \\
\hline Hepatic infarction & 2 \\
\hline Pulmonary oedema & 1 \\
\hline
\end{tabular}

Out of 38 patients, most common maternal complications seen are DIC and abruption placenta.

Table 7: Fetal complications.

\begin{tabular}{|ll|}
\hline Fetal complications & \\
\hline IUGR & 19 \\
\hline IUD & 1 \\
\hline Preterm delivery & 18 \\
\hline
\end{tabular}

Preterm delivery and IUGR accounts for most common fetal complications among HELLP syndrome patients.

\section{DISCUSSION}

In the present study the mean age of the population was 21.34 with a standard deviation of 3.74 years. The association with HELLP/ Partial HELLP was not significantly associated with the parity and the family history. There was a strong association of HELLP/ Partial HELLP with Pre-eclampsia and all the three tests that were considered to be the gold standard tests to identify the pathology. The three standard tests were platelet low count, hemolysis and elevated liver enzymes. The laboratory findings were in high contrast when compared to the normal. Three fold elevations were observed in liver enzymes and the platelet count was half of the normal value. Significant hemolysis was observed. BP was also elevated significantly. The maternal complication was seen to be drastic and it was found that even after prompt treatment the maternal and the fetal complications were significantly higher in number.

Abhijit Rakshi et al in their study has found and had similar observations. Our study is in complete agreement with the study conducted by them. ${ }^{9}$

The study conducted by Kjell Haram had studied similar complications and was noted in their study. ${ }^{10}$ Our study is also in full agreement with this study. But the complications that were observed in their study were much more. This may be because of the fact that the study sample was more in their study also the fact that the populations studied were different. 
The presenting symptoms, clinical findings, and many of the laboratory findings in women with HELLP syndrome overlap with a number of medical syndromes, surgical conditions, and obstetrical complications. Therefore, the differential diagnosis of HELLP syndrome should include any of the conditions such as upper respiratory infection, hepatitis, cholecystitis, pancreatitis, acute fatty liver of pregnancy (AFLP), or immune thrombocytopenic purpura (ITP). Because some women with HELLP syndrome may present with gastrointestinal, respiratory, or hematologic symptoms in association with elevated liver enzymes or low platelets in the absence of hypertension or proteinuria, many initially are misdiagnosed as having other conditions. Conversely, some women with other conditions such as TTP, HUS, systemic lupus erythematosus, sepsis, or catastrophic antiphospholipid antibody syndrome may be erroneously diagnosed as having HELLP syndrome. In addition, preeclampsia may occasionally be superimposed on one of these disorders, further contributing to the diagnostic difficulty. Because of the remarkably similar clinical and laboratory findings of these disease processes, even the most experienced clinician can face a difficult diagnostic challenge. Therefore, efforts should be made to attempt to identify an accurate diagnosis, given that management strategies may be different among these conditions. It is important to emphasize that affected women may have a variety of unusual signs and symptoms, none of which are diagnostic of severe preeclampsia. Pregnant women with probable preeclampsia presenting with atypical symptoms should have a complete blood count, a platelet count, and liver enzyme determinations irrespective of maternal BP findings. Occasionally, the presence of this syndrome is associated with hypoglycemia, leading to coma, severe hyponatremia, and cortical blindness. A rare but interesting complication of HELLP syndrome is transient nephrogenic diabetes insipidus. Unlike central diabetes insipidus, which results from the diminished or absent secretion of arginine vasopressin by the hypothalamus, transient nephrogenic diabetes insipidus is characterized by a resistance to arginine vasopressin mediated by excessive vasopressinase. It is postulated that elevated circulating vasopressinase may result from impaired hepatic metabolism of the enzyme.

\section{ACKNOWLEDGEMENT}

Authors thankfully acknowledge clinical unit heads of Obstetrics and Gynecology and Medical Superintendent of Mc Gann Hospital, Shivamogga for permission given to carry out the project.
Funding: No funding sources Conflict of interest: None declared

Ethical approval: The study was approved by the Institutional Ethics Committee

\section{REFERENCES}

1. Weinstein L. HELLP syndrome. Am J Obstet Gyneco1. 1982;9:95-111.

2. Sibai BM, Taslimi MM, El Nazer A. Maternal and Perinatal outcome in severe Pre-eclampsia/ eclampsia with HELLP. Am J Obstet Gyneco. 1986;155:501-9.

3. Sibai BM, Ramadan MK. Pregnancies complicated by HELLP syndrome: Subsequent pregnancy outcome and long-term prognosis. Am J Obstet Gyneco1. 1995;172:125-9.

4. Sibai BM, Ramadan MK, Usta I. Maternal morbidity and mortality in 442 pregnancies with HELLP syndrome. Am J Obstet Gyneco1. 1993;169:1000.

5. Gabbe SG, Niebyl JR. Joe Leigh Simpson Obstetrics- Normal and Problem Pregnancies $5^{\text {th }}$ edition. 2007:874-882.

6. Kim HY, Sohn YS, Lim JH. Neonatal Outcome after Preterm Delivery in HELLP Syndrome. Yonsei Medical Journal. 2006;47(3):393-8.

7. Isler CM, Rinehart BIL, Terrone DA. Maternal mortality associated with HELLP (Hemolysis, Elevated Liver and Low Platelets) syndrome. Am J Obstet Gyneco1. 1999;181:924-8.

8. Osmanagaoglu MA, Osmanagaoglu S, Ulusoy H, Bozkaya H. Karadeniz University, Turkey. Maternal Outcome in HELLP syndrome requiring intensive care management in a Turkish Hospital. Sao Paulo Medical Journal. 2006;124(2).

9. Rakshit A, Lahiri S, Biswas SC, Dey R, Roy BR, Saha MM. A study to detect HELLP syndrome and partial HELLP syndrome among preeclamptic mothers and their impact on fetomaternal outcome. Al Am een J Med Sci. 2014;7(1):20-5.

10. The HELLP syndrome: Clinical issues and management. A Review. Kjell Haram, Einar Svendsen, and Ulrich Abildgaard BMC Pregnancy Childbirth. 2009;9:8.

Cite this article as: Mallesara A, Kanta SR, Shivappa P. A clinical study of HELLP syndrome and its outcome in a tertiary health care system. Int J Reprod Contracept Obstet Gynecol 2016;5:4196-9. 